\title{
ACTITUDES EXPLÍCITAS ANTE EL RESALTE GRÁFICO EN LA TRADICIÓN DISCURSIVA PERIODÍSTICA ESPAÑOLA DE LOS SIGLOS XVIII Y XIX
}

\author{
EXPLICIT ATTITUDES TOWARDS TYPOGRAPHICAL \\ HIGHLIGHTING IN THE SPANISH JOURNALISTIC \\ DISCURSIVE TRADITION OF THE $18^{\mathrm{TH}}$ \\ AND 19 ${ }^{\mathrm{TH}}$ CENTURIES
}

\author{
Manuel Rivas Zancarrón \\ Universidad de Cádiz \\ manuel.rivas@uca.es
}

\section{Resumen}

Con el desarrollo de los tipos móviles de imprenta, la inclinación de la letra pasó de tener un efecto de formato general (solo se componían así libros con un contenido específico) a ser el indicativo de un proceso de alienación dentro del texto, en donde lo resaltado respondería a la necesidad del autor, redactor o cajista de querer desentenderse de las ideas o expresiones escondidas tras la letra inclinada. Con este trabajo queremos dar conocimiento del enorme potencial descriptivo que ofrece este elemento tipográfico para el análisis de las actitudes ante la lengua en un periodo concreto de la historia del español, pues el uso del resalte podría revelar en muchas ocasiones manifestaciones concebidas como no normativas o rechazos explícitos de expresiones que atentaran contra la pureza del idioma. Después de considerar los aportes metodológicos de la sociolingüística histórica y de la corriente que responde a la etiqueta de "tradiciones discursivas", hemos procedido a delimitar los usos de la letra cursiva según las manifestaciones explícitas aparecidas en la prensa española de los siglos XVIII y XIX. Este examen se concibe como un primer paso en la investigación del resalte tipográfico en textos periodísticos, pues serán los propios autores los que determinen cuándo y por qué se inclina la letra en lo impreso. Luego corresponde al investigador —en función del formato y tipo textual - extraer las actitudes que han llevado al autor, redactor o cajista a modificar la silueta de la letra.

Palabras Clave: sociolingüística histórica, actitudes lingüísticas, tradición discursiva periodística, siglos XVIII y XIX, ortotipografía

Abstract

With the development of the movable-type printing press, the inclination of letters went from having a general format (only books with a specific content were composed) to being indicative of alienation within the text, where the highlighted word would respond to the needs of the author, editor or typesetter who wished to distance them from the ideas or 
expressions hidden behind the inclined letter. With this work we want to acknowledge the enormous descriptive potential that this typographic element offers for the analysis of language attitudes in a specific period of the history of Spanish, since the use of this highlighting could reveal on many occasions declarations conceived as non-normative, or explicit rejections of expressions that attack the purity of the language. After considering the methodological contributions of historical sociolinguistics and that which can be labelled "discursive traditions", we have proceeded to delimit the uses of italics according to explicit displays which appeared in the Spanish press of the $18^{\text {th }}$ and $19^{\text {th }}$ centuries. This examination is conceived as a first step in the investigation of typographical highlighting in journalistic texts, since it is the authors themselves who determine when and why the letter is inclined in print. It is then up to the researcher-depending on the format and textual type-to find the attitudes that have led the author, editor or typesetter to modify the silhouette of the letter.

KEYwORDs: historical sociolinguistics, linguistic attitudes, journalistic discursive tradition, $18^{\text {th }}$ and $19^{\text {th }}$ centuries, orthotypography

FECHA DE RECEPCIÓN: 29/08/2018

FECHA DE ACEPTACIÓN: 03/11/2018

\section{Introducción ${ }^{1}$}

Quién podría aventurar que esa forma de componer la letra que Aldo Manuzio, allá por los inicios del siglo XVI, grababa en plomo se convertiría ahora en un posible método de análisis filológico. Sus moldes en manum mentita, aquello que se dio en llamar posteriormente cursiva, bastarda, grifa o itálica, reproducirían las formas caligráficas de la cancillería medieval, que gustaba de la inclinación de la letra a fin de reducir espacios y, así, disminuir los costes del material sobre el que se impregnaba la tinta. ${ }^{2}$

\footnotetext{
${ }^{1}$ Este trabajo se inscribe dentro del proyecto Corpus diacrónico para el estudio de las actitudes lingüísticas en América y España en los siglos XVIII y XIX (FFI2016-76874-P), concedido por el Ministerio de Economía y Competitividad del Gobierno de España. ${ }^{2}$ Como señala Cecilia Consolo, el comercio de libros manuscritos motivó la agilización de la caligrafía con un tipo de minúscula que, por ser creada en Italia, se denominaría itálica, y a cuya creación se asocian los nombres de Niccolò Niccoli y Poggio: "El comercio floreciente de libros manuscritos creó en Italia un sistema de fama y prestigio para los editores de libros así como para los escribas que eran empleados en las casas
} 
Del corte y figura de este molde fue responsable su colaborador, Francesco Griffo, quien supo ver las bondades del nuevo tipo en la creación de formatos más cómodos y compactos, los cuales agilizarían sin duda los incipientes y rudimentarios trabajos de impresión. La inclinación de la grafía se popularizó en los libros que traducían las obras clásicas, hasta el punto de convertir su silueta en un identificador del contenido, aunque muy pronto comenzó a alternarse con la forma redonda y a diferenciarse de esta por su función de resalte.

Y es precisamente el papel que se le reservará a la cursiva el que será objeto de este estudio, pues, según se tenga en mente una de sus posibles funciones, así podrá llegarse a una futura conclusión en torno a las actitudes que los hablantes tenían ante la lengua en un periodo determinado de su evolución. La importancia de detenerse en los moldes inclinados para la investigación filológica se justifica desde el momento en el que el resalte de una palabra o frase dentro de un cuerpo en letra redonda podría ofrecernos indicios de qué opinaba el autor de un texto sobre una forma gramatical o por qué el redactor o cajista - ya fuera el caso- que le ha dado vida en papel disentía de aquello que había recibido de forma manuscrita en algunas ocasiones. Téngase en cuenta que los moldes bastardos se usaban ya en el siglo XVIII como formas de expresar la alienación de un mensaje, tanto si la manifestación de este iba en la dirección autor real-mensaje, como en la de redactor o cajista-autor real (cf. Rivas Zancarrón, 2018a). En este punto, se hace preciso distinguir entre distintas manifestaciones textuales (en letras de molde y manuscritas) y discursivas (cartas privadas, periódicos, obras literarias, tratados gramaticales...), pues, según estos filtros, los corolarios en torno al resalte presentarán matices diferencia-

editoriales. Entre los nombres asociados a la minúscula humanística está también el de Niccolò Niccoli (1363-1437), quien al permitirse introducir en la minúscula cierta rapidez y espontaneidad logró el estilo que hoy denominamos 'itálica'. Niccoli y Poggio [Bracciolini] abrieron así el camino a las dos interpretaciones de la minúscula humanística que se convertirían en los dos grandes estilos italianos del siglo xv, base de nuestra escritura tipográfica: la redonda y la cursiva" (2013: 24). Para un mejor conocimiento de la historia tipográfica puede consultarse Corbeto y Garone Gravier (2015). 
dores. Podría ocurrir, así, que un redactor o cajista se hubiera servido de la letra cursiva para recriminar un uso lingüístico determinado del autor al que imprime $-\mathrm{y}$ con el que no está de acuerdo-, o bien porque este último realmente precisaba en su manuscrito la necesidad del resalte en lo impreso (normalmente indicado mediante un subrayado). Es indudable, por tanto, el valor que puede tener el detenimiento en estos focalizadores gráficos para el estudio de determinadas actitudes lingüísticas ante los aspectos gráficos, fonéticos, morfológicos, sintácticos y léxicos de la lengua, pues el resalte podría revelarnos datos sobre un estado normativo (uso de la inclinación de la letra como rechazo de un una expresión o grafía) y, consiguientemente, de las ideas o creencias en torno a diferentes manifestaciones diatópicas, diastráticas y diafásicas (cf. Rivas Zancarrón, 2018a).

Con objeto de demostrar el potencial descriptivo de esta forma gráfica en el análisis filológico, pondremos el foco de estudio exclusivamente en las actitudes explícitas que sobre el resalte en grafía se manifestaron en los siglos XVIII y XIX dentro de la tradición discursiva periodística. Se trataría ahora de dar el primer paso en la posibilidad de considerar el análisis del resalte como un motor explicativo del cambio lingüístico: cuándo, cómo y por qué se inclinaba la letra en los periodos indicados, y dentro de los espacios de opinión pública. Una vez respondidas estas preguntas, podrían iniciarse posteriormente estudios sobre actitudes implícitas en el uso de la cursiva, que revelarían detalles sobre las creencias normativas en un periodo determinado de la historia lingüística del español. Conozcamos, no obstante, algunos aspectos metodológicos previos que han sido considerados en este trabajo.

\section{Apostillas metodológicas}

No cabe duda de que la única información de que disponemos para conocer el estado lingüístico de los siglos puestos a debate está proporcionada por los textos, los cuales adquieren vida propia a través de las abstracciones del investigador. Cuantas más variables podamos añadir al reconocimiento de las peculiaridades lingüísticas de un texto, mayores posibilidades hay de preci- 
sar cuál fue la situación lingüística real de un periodo concreto en la historia de una lengua determinada. Para la creación de estas variables difícilmente puede recurrirse a los postulados de una lingüística inmanentista, más centrada en el funcionamiento de un mecano interior, que en la puesta en conexión de este sistema con la realidad exterior. En este sentido, ya Coseriu (1977), más preocupado en otros tiempos por desvelar el rodaje de las piezas internas que hacían funcionar la lengua, comienza entonces a aflojar la cuerda de su rigor metodológico para dar paso al análisis del contexto social. Este autor - que poco a poco relajaba su postura, centrada en el estudio del nivel más abstracto de la lengua, el sistema - comienza a abrir el abanico de análisis desde su concepción de los "tres niveles del lenguaje", una versión más simplificada de la axiomática bühleriana, en donde el Sprachgebilde, el acercamiento descriptivo más encorsetado y general a la vez, se libera con la consideración del acto verbal (Sprechakt), el aquí y el ahora de la comunicación. Los discípulos más allegados de Coseriu comenzaban a desarrollar las bases de una pragmática histórica, la cual pondría en duda algunas de las formas de acercamiento al objeto diacrónico, ya que se daba a entender que los textos se mantenían vivos por tener una historia (cf. Schlieben-Lange, 1973, 1975, 1983; o Dietrich, 1973). A partir de ese momento, empiezan a considerarse como pruebas e indicios para el rescate de elementos lingüísticos los vaivenes cíclicos, las épocas, los contenidos religiosos, jurídicos o periodísticos, la recepción del mensaje, el entorno sociocultural, y un largo etcétera. Estas primeras preguntas de la escuela de Tubinga, que nacieron con simultaneidad al desarrollo de la sociolingüística como ciencia (Labov, 1972) y al nacimiento del estudio de las actitudes lingüísticas en español (Rona, 1974; López Morales, 1989), abonaron el terreno de los frutos posteriormente recogidos por Koch y Österreicher (2011) y claramente transmitidos por Kabatek (2000), dentro de la etiqueta conocida como tradiciones discursivas. ${ }^{3}$ Es cierto que los textos no hablan,

\footnotetext{
${ }^{3}$ Años antes, Badía Margarit (1960) ya había intuido las diferencias entre diferentes tipos discursivos.
} 
pero sus usos y maneras se transmiten históricamente, por lo que son susceptibles de ser estudiados de acuerdo con esos lugares comunes cristalizados ahora en variables de acercamiento al objeto. El investigador, más que preguntarse por cómo se imbrican los elementos lingüísticos entre sí, debe ahora cuestionarse el carácter impreso frente al manuscrito de los textos, o la época en la que fueron escritos, así como su entorno sociocultural, o a quién va dirigido el contenido, o quién ha intervenido en la elaboración... Cuantas más preguntas se respondan, mejor cribados estarán los corolarios posteriores. Este motor descriptivo nos interesará para situar el texto en el entorno que le corresponda y relativizar las generalizaciones según una unidad discursiva concreta.

Y si para el estudio de las actitudes lingüísticas en los resaltes tipográficos habríamos de considerar algunos de los planteamientos metodológicos de las tradiciones discursivas y de la sociolingüística moderna, en el problema concreto de grafía que nos ocupa tendríamos también que adelantar algunos detalles. ${ }^{4}$ Sabemos, por algunos estudios ya emprendidos (Rivas Zancarrón, 2010, 2017a, 2017b, 2018a y 2018b), la importancia que tiene la ortografía como medio de análisis de las actitudes de la lengua y el impacto que esta ejerce sobre el cambio, pero aún se sabe muy poco sobre las repercusiones de la modificación de la letra en la conformación de las creencias en torno a la lengua y, consecuentemente, en su transformación. Este hecho no ha escapado a la observación de muchos tipógrafos, quienes han advertido su importancia en el desvelamiento de una forma de pensar lingüística. Es conocida a este respecto la opinión de

\footnotetext{
${ }^{4}$ El estudio de las actitudes lingüísticas empezó a cobrar interés en la década de los años setenta, en el momento en el que Labov esparciera la semilla de la relación entre lengua y sociedad. Naturalmente, la asimilación de lo lingüístico en lo social no solo ha tenido desarrollo dentro de la llamada "pragmática histórica", con la consiguiente formulación posterior de la teoría de las tradiciones discursivas, sino que esta disolución ha sido contemplada desde diferentes perspectivas, que van desde lo puramente actitudinal o creencial (Agheyisi y Fishman, 1970; Blanco de Margo, 1991; Blas Arroyo, 1999; Edwards, 1982; Milroy, 2001; Conde Silvestre, 2007; Rojas y Avilés, 2014, etc.), hasta el desate de conflictos en esa relación (Sarnoff, 1966), o la repercusión en lo psicológico (Giles y St. Clair, 1979).
} 
Garone Gravier, quien incide en las repercusiones de un conocimiento tipográfico más pormenorizado a la hora de considerar variables descriptivas certeras que filtren las conclusiones de un trabajo:

Además de estos ejes [criterios didácticos para enfatizar la enseñanza de la tipografía], los conceptos clave que estarían vinculados con el lenguaje, la comunicación y los tipos de discurso, o más específicamente, la lengua escrita, los eventos comunicativos que se presentan con recursos visuales y la enunciación de esos eventos, es decir, el tipo de presentación tipográfica, también conocido como puesta en página (2012: 9).

Naturalmente, la puesta en relación del elemento visual gráfico con las intenciones comunicativas y el uso lingüístico debe implicar necesariamente servirse del concepto de tradiciones discursivas anteriormente reseñado con objeto de desgranar los elementos que forman parte del filtro descriptivo, o en palabras de Garone Gravier:

No podríamos entender lo que pasa si no contáramos con un bagaje cultural, ubicado en un momento histórico, que hiciera comprensible una situación dada para los sujetos participantes en la comunicación. Como se puede apreciar, me refiero a los elementos modeladores del proceso de comunicación: enunciador-cliente, formalizador-tipógrafo-emisor, comunicación visual -tipográficamente expresada-, el modo particular de presentación - tipo o género discursivo-, el contexto de expresión - que vincula el mensaje particular que se está diseñando con el resto de los mensajes producidos-, y un destinatario-lector (2012: 19)

Esto viene a significar que el uso ortotipográfico variará según el formato de publicación, el rasgo de inmediatez que se asocia con determinadas impresiones, así como la periodicidad del texto que sale a la luz. Por esta razón, las manifestaciones de la cursiva, por ejemplo, serán diferentes si tratamos con formatos de libros - con una composición más laboriosa- a si tratamos con pliegos sueltos o de publicación seriada, en donde 
las posibilidades de corregir errores son mucho menores. De la misma manera, en la consideración de las actitudes lingüísticas en los resaltes gráficos influye también la naturaleza del capital en la que se publica el escrito (si estatal o privada), así como el contenido de la publicación (literario, político, económico, publicitario, etcétera).

Adviértase, no obstante, que las pretensiones de este trabajo se resumen en la selección de un corpus extenso de opiniones en torno al uso de la letra cursiva en la prensa de los siglos mencionados, de manera que la correlación entre estos aspectos metodológicos y el resultado de sus corolarios serán, en este caso, más un avance de los principios que regulan la mente del investigador, que un hilo conductor que determine la justificación de las variables finales. Dicho así, se precisaría llevar a cabo un trabajo pormenorizado no de las opiniones explícitas en torno al fenómeno de la cursiva, sino de la manifestación real de este fenómeno sobre los textos periodísticos, pues solo así se podrá concluir el universo de creencias y actitudes en torno a cada término o expresión resaltados bajo este proceder gráfico.

Contemplados estos detalles terminológicos de acceso al objeto, iniciaremos ahora nuestra aportación al estudio de las actitudes explícitas ante el resalte gráfico en la prensa española de los siglos XVIII y XIX, pues ha de contemplarse como paso previo al análisis de manifestaciones concretas, y que será objeto de futuros trabajos.

\section{Actitudes explícitas ante el resalte gráfico en la tradición discursiva periodística española de los siglos XVIII y XIX}

\subsection{Sobre el corpus y las variables del estudio}

La búsqueda de actitudes explícitas en la prensa de los periodos neoclásico y decimonónico españoles ha permitido construir un conjunto de variables de uso sobre los resaltes gráficos que, en algunas ocasiones, contrasta con los manuales de tipografía de la época, además de ofrecer una información valiosísima sobre 
la aparición de la letra inclinada en los diferentes tipos discursivos. ${ }^{5}$ Setenta y cuatro publicaciones seriales hemos rastreado en un periodo que se extiende desde el primer tercio del siglo XVIII hasta finales del XIX, las cuales han sido consultadas desde la hemeroteca digital de la Biblioteca Nacional de España. Las manifestaciones extraídas nos dan una idea de cómo actuaban los impresores respecto del uso de la cursiva o bastardilla, hecho este que permite generar las primeras conclusiones sobre qué elementos se ponían en foco, cuál era el motivo y quién practicaba el resalte (si autor, redactor o corrector-cajista). ${ }^{6}$ Estos detalles, manifiestos de manera explícita, son de enorme interés a la hora de evitar atribuir los efectos del resalte a un autor concreto, pues, como se anuncia en muchas ocasiones, se inclinaba la letra por el desacuerdo en una expresión entre el autor y el redactor, siendo así que el foco creado gráficamente se erige en un efecto de alienación por parte de este último al querer desentenderse de las palabras del primero. Es aquí donde pueden aflorar la mayor parte de actitudes implícitas ante la lengua, así como la

\footnotetext{
${ }^{5}$ Adviértase que muchas imprentas trabajaban con manuales tipográficos, en donde se dejaban claros los usos de la cursiva en el momento de imprimir un texto. Muchas de estas empresas de impresión recurrían a estudios de ortografía ya consolidados, los cuales iban desde las Reglas de orthographia en la lengua castellana de Nebrija, hasta manuales como los de Mateo Alemán (Ortografía castellana, 1609). En la Institución y origen del Arte de la Imprenta y reglas generales para los componedores, De Paredes (2002 [1680?]) reconoce acudir a obras como el Vocabulario de las dos lenguas toscana y castellana (1570), de Cristóbal de las Casas, o la Suma de ortografía castellana (1593), de Guillermo Foquel, o las explicaciones ortográficas, según la doctrina de Felipe Mey en el Thesaurus verborum.

${ }^{6}$ Debe precisarse también, como advierte Garone Gravier (2015), que el oficio de corrector, el cual podía ser ejercido por el impresor o cajista, se prestaba a ambigüedades, pues designaría tanto al destinatario de los saberes promulgados en los manuales de imprenta (a los que se les presuponía también conocimientos de composición y gramática), como a los oficiales de la Corona, habituales desde la pragmática de Valladolid de 1558. En este último caso, o sea, el corrector oficial, debía seguir las indicaciones del Consejo de Castilla y reduciría su intervención al cotejo exclusivamente de contenido con el original al que se le había dado el visto bueno. Por esta razón, Garone Gravier (2015: 28) insiste en que las normas ortográficas y tipográficas de los impresores o cajistas solo pueden reconocerse en los "originales de imprenta", donde se ve el cambio al uso de mayúsculas, signos de puntuación, partición de palabras, utilización de cursivas, etcétera (cf. Rivas Zancarrón, 2018a y 2018b).
} 
opinión encubierta de los hablantes de una época sobre su uso normativo (cf. Rivas Zancarrón, 2017a).

No es objeto de este trabajo un acercamiento a la prensa española de los siglos puestos a debate, pues muchos han sido los investigadores que la han tratado con minuciosidad, aunque sí se han tenido en cuenta las consideraciones de estas investigaciones a la hora de identificar las variables en el resalte gráfico. Tampoco vamos a entrar aquí en la fructífera discusión que planteó Rizzini (1968) sobre la relación entre imprenta y periodismo, en la que se concluía que este último debe más al correo que a la imprenta, pues la distribución de cartas privadas manuscritas, como corredoras de información, estaban sujetas a menor censura que la exposición en molde. Desde esta perspectiva, un estudio de este material podría también ofrecernos pistas sobre el enfoque gráfico en lo manuscrito, normalmente realizada mediante el subrayado, pero no tan habitual como en los textos impresos. Eso sí, en la relación entre imprenta y periodismo ha sido necesario considerar dos variables con repercusiones en el análisis de las actitudes lingüísticas desde el punto de vista de los resaltes: 1) el rasgo de deseable 'inmediatez' atribuible a la prensa periódica, que presupone una recepción cuantitativa mayor que otras publicaciones, y 2) la identificación de propiedad de la imprenta (si estatal o privada). En el primer caso, como señaló Mourenza (1977), el oficio de cajista, debido a la premura de sacar el producto a la luz lo antes posible, cobró mayor importancia, pues pasó de ser un simple obrero manual a un elemento activo en la redacción. Este hecho da a entender que en el control de la ortografía y tipografía originaria era el cajista o redactor el que tenía la última palabra, por lo que poco se puede saber sobre la presentación gráfica original. En el segundo caso, la disposición gráfica de las imprentas estatales se acomodaban más a los dictados de corporaciones académicas, aunque, en lo que concierne a España, la variación es mínima respecto de lo que acontece en zonas americanas como Costa Rica (cf. Rivas Zancarrón, 2018a).

Pues bien, tras una amplia ojeada a un extenso corpus de periódicos españoles de los siglos XVIII y XIX, se pueden adelantar cuatro variables o usos de la cursiva, que se coligen de 
manifestaciones explícitas realizadas por redactores o autores de artículos específicos. De ellas, las más interesantes son las que corroboran el porqué de la inclinación del tipo para focalizar el uso de una expresión que no responde a una norma concreta. Para la selección de las opiniones en torno a este fenómeno gráfico, nos hemos adentrado en la hemeroteca digital de la Biblioteca Nacional de España y hemos procedido a sortear la información - de las innumerables publicaciones periódicas aparecidas en los dos siglos tratados- desde el punto de vista cronológico y de contenido, de manera que pudiéramos hacernos una idea tanto de la evolución del uso, como de la manifestación de opiniones según la tipología textual del periódico (económico, político, satírico...). Solo así podrá revelarse luego si la ideología que descubren los términos resaltados tiene una mayor justificación por el tipo de texto.

Así pues, los cuatro usos que pueden destacarse tras el rastreo de manifestaciones explícitas son los siguientes: 1) cursiva como resalte de obras, términos, fechas y fiestas; 2) cursiva y énfasis de la información por resalte de palabras clave (foco/ presuposición); 3) cursiva y las palabras del otro (citación, traducciones, ampliaciones, reducciones...), y 4) cursiva y actitudes lingüísticas explícitas. Ciertamente, las tres primeras representan comentarios y opiniones que atienden más a una tradición textual que discursiva y responden a valoraciones de tono estilístico. De estas cuatro variables, la más interesante para justificar un estudio posterior sobre la importancia del resalte en la revelación de actitudes lingüísticas es, naturalmente, la última.

\subsection{Cursiva como resalte de obras, términos, fechas y fiestas}

Las manifestaciones explícitas que en torno a la cursiva se dejan ver en la prensa española del periodo estudiado podrían conformar una auténtica poética de uso de las imprentas. Las primeras referencias que atañen al tópico de este epígrafe - independientemente del uso material que se le daba a la cursiva- las encontramos en el número 200 del Diario de Madrid, publicado en 1806, en el que se reseña un manual de instrucción escolar, 
y en donde se advierte de la virtud de focalizar en bastardilla el país al que se asocia un traje típico. El resalte debe emplearse aquí como un facilitador nemotécnico:

Abecedario útil para la instruccion de los niños de primera educacion, compuesto de veinte y siete figuras con los trages que á cada una le corresponde, señalando con toda claridad las letras mayúsculas, romanilla, y el pais de cada trage en letra bastardilla, con el número que á cada figura pertenece, hecho con el mayor gusto y esmero, para que al mismo tiempo que sirve á los niños de diversion, se les quede impreso en la memoria todo lo que este tan útil (Diario de Madrid, 1806, núm. 200, p. 83).

El periodo de las Cortes de Cádiz es quizá el más prolijo en indicaciones, debido, muy posiblemente, a la necesidad de prestar foco a determinadas noticias y publicaciones. En estos momentos de intensidad política, se precisaba de resaltes continuados. Las referencias a otros periódicos de información eran constantes y los títulos de estos habían de iluminarse en bastardilla:

Si en el impreso de la junta se hubiese copiado el parrafo segun está, no hubiera podido atribuirseme la intencion de querer privar á las autoridades de Santander de las que es la junta, del honor de lo que hicieron, y por eso puso esta no todo ni por el órden de ideas por mi dispuesto, sino como manifiesta su impreso, y con letra cursiva para hacer mas notable el periodico (El Bascongado, 1814, núm. 21, p. 170).

Un efecto normativo curioso, que ya Capmany exigió, fue el resaltar de cursiva en todos los calendarios el día en el que se conmemoraba los mártires caídos durante la Independencia española:

El Sr. Capmani hizo presente que no se habia cumplido la resolucion de S. M. para que en los calendarios se ponga en el dia 2 de mayo de letra cursiva: Conmemoracion de los primeros martires de la idependencia española (El Conciso, 1812, núm. 27, p. 1). 
Por lo demás, era costumbre exigida que determinados fenómenos de la naturaleza, así como las fiestas de guardar se colocaran también de cursiva, como se lee en los siguientes fragmentos:

Los meteoros que se observen fuera de las tres épocas se escribirán con letra bastardilla, á escepcion de la lluvia, que se conocerá por el Udómetro ó Pluviómetro (Nuevo diario de Madrid, 1821, 1 de septiembre, p. 3).

Nota.- Las fiestas movibles van puestas en letra bastardilla y pueden verse los dias en que se celebran en el lugar donde se mencionan todas, antes del Almanaque (Guía de Sevilla, 1875, p. 83).

De manera indirecta y burlona, algunos articulistas dan cuenta de la costumbre de resaltar en bastardilla determinadas efemérides, uso que se reservaba exclusivamente para días señalados o cumpleaños de gobernantes:

¡Dichoso Abril! Que entras con San Venancio, y sales con San Pelegrin.

Interpélo á todos los amigos de mi lego Fray Pelegrín TiraBEQUE, para que me digan las causas por qué han caido en el descubierto de no felicitarle ayer por los dias de su santo y su cumpleaños. Si bien en parte no es de estrañar esta falta, puesto que su santo no se anunció con serenatas y salvas de artillería como se anunció el miércoles el cumpleaños de la reina Cristina, ni en el almanaque se prescribia el sábado como el miércoles en letra cursiva la Gala con uniforme, que lleva trazas de durar tanto como la Bendicion papal en el Carmen y la Absolucion general en la Merced (Fr. Gerundio, mayo de 1842, p. 17).

Y conforme avanza el siglo xIX, ya casi a su final, se confirman explícitamente las intenciones de los impresores de inclinar la letra en función metalingüística: 
3. ${ }^{\text {a }}$ En am ó ama se puede apreciar el tipo de letra adoptado para las radicales; en ene ó ese el que nos ha parecido bien para las características; las desinencias se destacan por la letra bastardilla, y para no confundir los elementos ligativos ó eufónicos, que se aprecian en $v a-y-a, v-o-y$, etc., se ha escogido tio diferente ( $L a$ Escuela Moderna, agosto de 1899, p. 123).

Todos los nombres indígenas van escritos con letra bastardilla é indicando su pronunciación aproximada por medio de los signos siguientes:

$g h$, sonido especial que participa de las dos letras y aún de la $\mathrm{r}$, pareciéndose al que dan á esta tercera los parisienses... (Revista de Geografia Comercial, 1 de enero de 1894, núm. 125, p. 1).

La preocupación por la edición de textos llega a los articulistas de publicaciones seriadas, quienes advierten la necesidad de una pulcra composición tipográfica en los libros que se imprimen:

Los prólogos van generalmente en carácter redondo, uno ó dos grados más grueso que el del texto, y con numeracion romana en los fólios; los índices suelen componerse en bastardilla, á no ofrecer esto dificultad por su mucha extension, y en ese caso se empleará carácter redondo, pero de menor cuerpo ${ }^{7}$ (El Averiguador Universal, 31 de agosto de 1880, núm. 40, p. 253).

Un detalle interesante que habría de tenerse en cuenta en la evolución del sistema ortotipográfico del español es la asunción de responsabilidades en la correcta composición de un texto. Durante el siglo XVIII, la preocupación del autor material de un escrito se enfocaba casi exclusivamente sobre el contenido, en tanto que la elaboración formal corría a cargo de los editores o los cajistas (de aquí que, en cierto modo, el respeto de una norma ortográfica, y por necesidades de economía, solo fuera

\footnotetext{
${ }^{7}$ Las mismas indicaciones aquí dadas se reproducen en la página 57 del Boletín Histórico, publicado en abril de 1882.
} 
atendida por estos y no por la gente de a pie). Poco a poco, y sobre todo a finales del siglo xix, el autor debía hacerse cada vez más responsable de qué escribía y cómo lo escribía, por lo que muchos editores se quejaban de los descuidos en los envíos manuscritos, que obligaba a intervenir al cajista para su corrección:

En un original bien arreglado, debe el autor subrrayar las palabras ó períodos que desee se compongan de cursiva, poner dos rayas debajo de las palabras que quiera vayan de versalitas, y tres rayas si, para hacerlas resaltar más, prefiere las mayúsculas o versales; una raya undulada indica la egipcia. Empero como no siempre los autores se han tomado ese trabajo, hay necesidad de corregirlo en pruebas, áun cuando causa perjuício al cajista, por lo cual es conveniente sepa el olvidadizo que para hacerlo ha de seguir las antedichas reglas. Cuando el corrector quiera que se varie el tipo de lo que en la prueba aparezca de cursiva, versalitas, versales ó egipcia, se subrrayarán tambien, haciendo, para evitar dudas, una de las siguientes indicaciones marginales: $r{ }^{o}$ (redondo), c. ${ }^{a}$ (cursiva), $v^{a}{ }^{a}$ (versalitas), $V \cdot^{a}$ (versales) y eg. ${ }^{a}$ (egipcia) ( $E l$ Averiguador Universal, 31 de agosto de 1880, p. 247).

Es de muy mal efecto, por otra parte, el ver impresa en un libro, y acaso en una misma página, de dos distintas maneras una misma palabra; pero nada más fácil, pues acaso el autor al tiempo de escribir el original no se cuidó de esto, y el cajista copió lo que tenía delante de los ojos, ó son varios los que trabajan en la misma obra y no se pusieron de acuerdo. De todas suertes, al corrector incumbe remediar tan gran defecto (Boletín Histórico, abril de 1882, núm. 4, p. 55).

Estas advertencias, de las que no hay manifestaciones explícitas durante el siglo XVIII, determinarían el uso de la cursiva con intenciones actitudinales, pues, dependiendo del periodo, hablaríamos, por ejemplo, de actitudes puristas en el redactor (que no tienen por qué coincidir con el autor) o en el articulista real. Por esta razón, durante el siglo XVIII, los fallos en el uso de la cursiva se achacaban más al cajista o componedor que al autor del artículo: 
Nota. En el Diario de ántes de ayer pag. 415 lin. 13 se padeció la equivocacion de imprimir dos versos como si fuesen uno, y la de poner de letra bastardilla el uno de ellos (Diario de Madrid, 17 de abril de 1788, p. 424).

\subsection{Cursiva y énfasis de la información por resalte de palabras clave (foco/presuposición)}

La costumbre de iluminar en bastardilla determinadas palabras clave, en donde interesa que el lector centre la atención del mensaje, fue habitual ya desde el siglo XviII en la prensa española, aunque sin saber con seguridad si el resalte era provocado por el articulista o por el redactor. ${ }^{8}$ Téngase en cuenta que en esa época muchas de las noticias se recababan literalmente de otros periódicos o eran traducciones de alguna información publicada en el extranjero. Debe advertirse igualmente que una imagen habitual durante el siglo XVIII era ver en boticas y otros espacios de opinión pública a una persona encargada de leer en voz alta las noticias, dado que el grado de analfabetismo impedía la lectura directa. Muy posiblemente, estos elementos resaltados debían corresponderse con elevaciones tonales en la emisión a viva voz $y$, difícilmente, su intención de resalte provendría del articulista, sino del redactor. Por esta razón, es complicado encontrar manifestaciones explícitas sobre el uso de la cursiva con función focalizadora durante el periodo neoclásico. Las primeras alusiones con este cometido las hemos hallado en el serial $E l$ Castellano, y data de 1836:

Hemos marcado de intento dos períodos de bastardilla, para que se vea que entonces á nadie pasaba por la imaginacion el disputar la inconveniencia del veto absoluto; disputábase únicamente acerca de que el rey hubiese de dar necesariamente la sancion, ó pudiese suspenderla (El Castellano, 23 de diciembre de 1836, p. 2).

\footnotetext{
${ }^{8}$ Hay que tener presente que el que escribía el artículo podía o no coincidir con el redactor del periódico.
} 
Muy distinto - respecto de la autoría del resalte con esta función- parece ser lo que acontece a partir del segundo tercio del siglo XIX, pues se tiene claro que la cursiva es responsabilidad del articulista, aunque muchas veces este coincidía con el redactor. Son las noticias de contenido político las más afectadas por estos focos gráficos:

Todas las cosas pues y todas las personas existentes, deberian unas temer y otras esperanzar y aun exigir que se las reformára en el sentido de los principios de progreso en todo y para todos.

Estas dos palabras, cuya importancia su autor ha querido señalar muy espresamente poniéndolas en bastardilla, hasta sin querer nos traen á la memoria aquellas muy parecidas del general Espartero en los dias de su denominacion: "La paz no será turbada por nada ni por nadie” (El Áncora, núm. 555, miércoles 9 de julio de 1851, p. 130).

Las intenciones son más claras aún en las manifestaciones explícitas de publicaciones satíricas, en donde se dejan claras las intenciones del autor a la hora proceder a inclinar la letra:

Y esto de ojo, y de cubero me recuerda lo que tantas veces repetí en la capillada 87. “Ojo á la Isla de Cuba!” dije entonces: ojo á esa preciosa joya, llave y emporio del comercio de ambos mundos! Seis veces dije: “Cuidado con ella!" Y si no tres, á lo menos dos ojos se han de ver alli de letra bastardilla. Y cuando Fr. Gerundio echa su bastardilla, sus dos ó tres ojos, y su media docena de cuidados en una capillada, es prueba de que aquella capillada tiene intríngulis (Fr. Gerundio, 15 de enero de 1839, p. 86).

En realidad, se trata de un mecanismo que contrapone la información nueva a la conocida, por lo que la cursiva se reservaría para aquellos elementos de la frase (sea sustantivo, adjetivo, verbo o complementos) que aporten la novedad de la noticia:

Nuestro ilustrado colega, no ha podido menos de reconocer que en la esencia existe la distincion que sostenemos, pues dice "que 
el liberalismo religioso y el liberalismo político, hoy en la prácti$c a$, (y pone tambien en bastardilla esta palabra) son una misma cosa" (La Dinastía, 16 de febrero de 1884, núm. 194, p. 1043).

En algunos casos, algunas publicaciones critican el abuso de la cursiva con fin focalizador por creer que se está manipulando la noticia, ya que la iluminación de la letra va reconduciendo inconscientemente la idea que trata de imponer el articulista: ${ }^{9}$

Habiendo demostrado nosotros que las doctrinas de LA España CATólica consisten en organizar el Estado á su gusto para que despues el Estado sea intolerante y perseguidor, para lo cual seria preciso que tuviera en el Estado una confianza que de ningun modo está justificada, LA España CATÓLICA, desfigurando violentamente nuestras frases, quiso, por medio de un gran aparato de letra bastardilla, de versales y de versalitas, hacer creer que nosotros no dábamos al Estado en España mas vida posible que por quince ó veinte años. Rectificamos tan absurdo comentario, y La España Católica tuvo la buena fé de no tomar en cuenta nuestra rectificacion. ¿Es en esto en donde ha visto nuestra derota y nuestra fuga? (La Época, 10 de junio de 1875, núm. 8263, p. 2).

Déjese, pues, La España Católica de adjudicarse victorias sin combatir; déjese de insultos, y de letras gruesas, y de palabras mas gruesas todavias, y de accidentes tipográficos estraordinarios, y de proposiciones estrafalarias, cuya única importancia

\footnotetext{
${ }^{9}$ Sin embargo, el abuso generalizado de la cursiva se critica en fragmentos como el siguiente: "La Vanguardia ha querido decir la última palabra. Por lo visto, al suponer que daba por terminada la polémica, creyó que no habiamos de contestarle y diría para su capote 'yo hablaré la última y quedaría la razon de mi parte'.

Como no gustamos de dar lanzadas á moros muertos, no queremos mortificar á nuestro colega poniendo nuevamente de manifiesto sus constantes caidas y tropiezos pero ya que el colego se muestra tan aficionado á la bastardilla le diremos en carácter corriente, para no molestar á nuestros cajistas, 'que los conservadores están muy ufanos y sastisfechos de la parte que han tenido en el plan de carreteras provinciales, en unión con los señores Marcet, Miljans, Henrich, Prats, Taulina, Soler y Arola, Jover"' (La Dinastía, 1 noviembre de 1885, núm. 1227, p. 6).
} 
consiste en ocultar con ellas la falta de contestaciones necesarias y de rectificaciones justas (La Época, 10 de junio de 1875, núm. 8263 , p. 2).

En el próximo epígrafe, daremos cuenta del uso de la cursiva en la reproducción literal de textos, pero bien es cierto que este efecto tipográfico trataba de dar a entender que lo focalizado era una idea perteneciente a otra persona. Si se quería reproducir palabra por palabra el mensaje del otro, se recurría siempre al entrecomillado; por esta razón, en algunos fragmentos como el que sigue, se advierte del cambio tipográfico para la recuperación de una idea no expresada literalmente:

Las frases anotadas de bastardilla indicaban únicamente que nuestro recuerdo era incompleto, y como no teniamos á la vista ningun documento que nos diera las interesantes noticias que despues ha tenido la bondad de suministrarnos el Sr. Lizazur y Paul, éranos de todo punto imposible satisfacer el vivo deseo que sentiamos de hablar acerca de las conferencias agrícolas en Cádiz (Gaceta Agrícola del Ministero de Fomento, 1877, tomo II, p. 271).

Por último, el mismo hecho de que los redactores advirtiesen de vez en cuando que la cursiva no era motivada por ellos, sino por los autores que envían el escrito, prueba que este focalizador gráfico pudiera ser usado indistintamente por ambas partes (el que escribe y el que imprime), sin que aparentemente se distinga el agente real:

Lo cual interpretaban los fusionistas côté D. Segismundo como síntoma de que, por ahora, suspende el elemento civil de los conspiradores los trabajos que llevaban entre manos para la perturbación del orden público.

Es de advertir que no nos pertenece la idea ó la ocurrencia de haber escrito en bastardilla esas tres palabras, "el elemento civil", que va en el párrafo anterior.

Eran los ministeriales los que subrayaban la frase, como si quisieran hacer notar bien que el señor Moret solo está tranquilo por lo civil y que, cuanto á lo militar, se lava las manos y declina 
toda responsabilidad en el ministerio de la Guerra, á quien tiene tan buena voluntad como todos sabemos (La Monarquía, 2 de septiembre de 1888 , p. 3).

\subsection{Cursiva y las palabras del otro. Ampliaciones y reducciones}

Desde un primer momento - en el periodo tratado, claro está-, la prensa asumió el valor de la cursiva como un efecto tipográfico alienante. Con su efecto visual, se añadía una información que no era aportada por el articulista o transmisor del mensaje, sino que partía de otras fuentes con las cuales se quería mantener una determinada distancia, o sea, es un "escribo yo, pero no lo digo yo". Y es ese distanciamiento el que consigue otorgar a la inclinación tipográfica un valor de desentendimiento, y de ahí su importancia para el rescate de actitudes ante la lengua. Esta función cuenta con manifestaciones explícitas tempranas, como la que reproducimos a continuación del Mercurio histórico y político:

Por esta causa suprimimos en el presente Mercurio, las deprecaciones, que al fin de èl hacen los Olandeses. En lo demás en que se dexa correr la narrativa, si la noticia esta siniestra, ò diminuta, le ponemos las addiciones con las señales que quedan advertidas, porque assi me ha parecido conveniente para la mas exacta instruccion de los aficionados à estas materias. VALE (Mercurio histórico y político, 1738, pp. 9-10).

Este valor alienante está en la mente de múltiples articulistas que sobreentienden en la cursiva una forma de escaparse de las ideas originales:

Afirma que al dirigirse al señor ministro que habla, en primer término ha hecho perfectamente, puesto que por su Ministerio se ha tramitado la nota diplomática, extrañándose que un político tan formal como el señor marqués de la Vega de Armijo se fije en detalles, como si el documento llevase letra bastardilla ó si es del número 7 ó del 8, explicando que lo que va de letra cursiva 
indica que no es del Gobierno español, sino que se transcribe de la duración del Vaticano (La Unión, 13 de abril de 1885, p. 2).

Ya advertíamos que la inclusión de la cursiva en un cuerpo textual podría responder también a la intercalación de traducciones o extracciones de otros periódicos, aunque lo más habitual era recurrir al entrecomillado cuando la reproducción respondía a letra por letra. ${ }^{10}$ En el siguiente fragmento, se critica un uso ambiguo:

Las palabras de letra cursiva que se ponen como textos de las actas y periodicos de aquellas Provincias sin citar individualmente de donde se han extraido cada uno, tienen contra sí, á mas de esa sospecha, la general de un periodico en donde se lee tan variado el diario de Cortes un curso, que todavia se repite en este número estar copiado fielmente á la letra, con animo sin duda de alarmar á los que no quieran tomarse el trabajo del cotejo (El Censor General, 1811, núm. 27, p. 67).

Dado que los periódicos del siglo xviII estaban más habituados a incluir traducciones de sus homólogos extranjeros,

\footnotetext{
${ }^{10}$ Ya en 1805 parecía constituir tono general en la prensa española el diferenciar entre el uso de la cursiva y el entrecomillado: "Parece ocioso advertir que lo que va entre comas es tomado de las obras de que aqui hablamos; lo de letra cursiva es lo que mas nos ha disonado ó llamado la atencion, queriendo fixar en ello lo del público" (Minerva o El Revisor General, 1805, p. 75). En cualquier caso, la ambigüedad tipográfica motivaba errores, quizá intencionados, de interpretación: “¿Tratándose de tan excelente y clásico poeta como el Padre Fonseca, habrá quien dude que esos versos copiados en bastardilla no son los mismos que su pluma trazara, sino que la impresion los ha descuadernado?" (La Ciencia Cristiana, 1878, vol. 5, p. 449). O el siguiene fragmento que reproducimos de La Esperanza: "El sofisma es evidente: en el artículo del Concordato no hay esas frases presidente del cabildo de las catedrales y presidente del cabildo de las colegiatas que La Epoca pone en bastardilla, como si fuesen testualmente copiadas de la ley: nombra al dean y las prebendas de oficio: declarando que las demas dignidades, es decir, las dignidades no nombradas, no esceptuadas espresamente, se proveerán alternativamente por la Corona y los Prelados" (La Esperanza, 10 de junio de 1863, p. 161).
} 
será en ellos donde más alusiones encontremos a las adiciones o reducciones practicadas sobre el original: ${ }^{11}$

Lo que en las paginas 21. 106. 109 y en la referida 142. encontrares de cursiva, son adiciones, que unas para mitigar, y otras para esclarecer la noticia, me pareciò conveniente el añadirlas. De aqui en adelante conoceràs lo addicionado en estàr de letra cursiva entre parentesis, con un $\mathbf{g}$. por guia; con el supuesto, de que en puntos de Religion, ò del Estado, ò lo que accessoriamente se opusiere à uno, y otro, no podemos ser imparcial dexandolo correr con la lisura que ello viene (Mercurio Histórico y Político, 1738, núm. 2, pp. 9-10).

En realidad, se reservaba la bastardilla para las interpretaciones que el redactor hacía de una determinada información, en donde este practicaba adiciones o sustraciones a un mensaje del que no se conocía muy bien la literalidad o del que, aun conociéndola, se permitía el lujo de reintrepretar. En los procesos de edición, seguía sin verse claro cuándo era usada la cursiva en el original manuscrito (resaltada mediante subrayado), o cuándo resaltaba el editor por algún motivo no especificado:

Empléala Aguirre tal como Fray Luis de Leon la usó cuando decía: Acude, corre, vuela, No perdones la espuela,

No des pazá la mano,

"No deis paz á la mano" - es casi seguro que Aguirre lo escribiera pensando en el poeta de Belmonte. Debió, pues, entre-

\footnotetext{
${ }^{11}$ Naturalmente, la cursiva no solo se usaba para las traducciones de fragmentos de periódicos extranjeros, sino también para la reproducción de publicaciones en la misma lengua: "Tenemos gacetas de Madrid hasta el Fin de Enero. De ellas hemos copiado los siguientes artículos que no pueden negar su tenebroso origen. Las notas que algunos tienen en bastardilla son del Gacetero real. Creemos que su publicacion agradará á nuestros lectores, porque con ellas conocerán la imprudencia con que el Gobierno español engaña á sus súbditos sobre el estado de América, y el espíritu que le guia. Su estupidez es tal, que no necesitan comentarios" (Gazeta del Gobierno de México. Gaceta del Gobierno Supremo de la Federación Mexicana, 1826, núm. 3, tomo 1, p. 1).
} 
comar dichas seis palabras ó hacer distincion de ellas con diferentes tipos á los comunes del escrito, porque ni es de suponer que Aguirre coincidiera en pensamiento y forma con el teólogo vate, ni razonable suponer que el escritor bilbaino desconozca la composición de quien escribió para honra literaria nuestra, y en la que se insertan los anteriores versos [...]. Tambien es coincidir demasiado en idea y modo de expresarla para no deducir que Aguirre debia emplear la letra bastardilla en momentos en que no lo hace (Revista de España, julio de 1872, núm. 27, p. 143).

Podríamos añadir muchas más manifestaciones explícitas sobre el uso de la cursiva como reflejo de la alteridad, pero baste señalar que, la evolución desde el siglo XVIII en este aspecto se resume en una trayectoria de foco basada en la traducción de noticias de prensa extranjera, en donde la literalidad no es lo pertinente, hasta la creación de una ambigüedad en el contenido del mensaje (intencionado o no) por ocultamiento del agente real de lo que se quiere transmitir. En cualquier caso, eran los periódicos satíricos y, sobre todo, los de contenido político, aquellos que más se servían de este tipo de letra, pues la ironía - recurso que juega igualmente con la ambigüedad - encontraba resolución explícita en la forma inclinada. En este sentido, sería interesante estudiar por qué era habitual el uso de la cursiva en algunas publicaciones y por qué en otros escaseaba, hecho este del que eran consciente algunos periódicos:

Los Tiempos esplican esto diciendo: — "Verdad es que el Sr. Sabater ha hecho su modesta fortuna á riesgo siempre de empresas algunas veces comprometidas.

Pongo de letra cursiva algunas palabras solo por seguir la manía á Los Tiempos" (Gil Blas. Periódico político satírico, 10 de junio de 1865, p. 1).

Y muchas veces, esta manía de focalizar cada palabra o expresión no era bien entendida por algunos articulistas, e, incluso, eran objeto de autocrítica, pues el abuso neutralizaba su función de resalte, ya que el ojo divisaba un cuerpo textual en donde lo inclinado se igualaba a lo redondo: 
Mas, basta ya, pues temo acabar con toda la bastardilla que posee esa imprenta, y, lo que sería más sensible, levantarle á V. y á mis lectores una jaqueca que no se les cure en tres semanas. Sobra con lo citado para convencerse de que el señor Loumo se estrena bien, y goza de todo lo necesario para dar, en breve tiempo, consigo en......un manicomio (Revista Contemporánea, octubre de 1866, núm. 64, p. 166).

\subsection{Cursiva y actitudes lingüísticas explícitas}

Quizá sea este el apartado que pueda resultar más productivo a la hora de valorar cómo se usaba la cursiva en los siglos XVIII y XIX, y con objeto de desvelar una actitud ante la lengua. De todos los periódicos analizados, hemos encontrado del siglo XVIII solamente una referencia explícita al uso de este tipo de letra con intenciones de encubrir un fallo normativo. La reflexión es interesante, pues explicita la función de alteridad que ejerce la cursiva a la hora de excluir de la lengua castiza algunos términos o expresiones focalizadas, aunque se proponga que puedan ser aceptados por la norma, y, más concretamente, por la Real Academia Española:

-En este caso se hallan escritas con letra bastardilla en los siguientes pasajes, tomados casi todos los respetables autores modernos, en su mayor parte académicos:

El impaciente agrícola

Entona loores al pródigo Abril.

Breton

No osa mover la planta atras ni alante.

Arriaza

Pisaban inexpertos los vergeles

Del aromoso eden...

Reinoso, etcétera

¿No deberian incluirse todas, ó casi todas estas palabas en el Diccionario de la lengua castellana? (El Averiguador, 15 julio de 1781, n. 14, p. 210). 
El resto de manifestaciones pertenecen al siglo XIX $-\mathrm{y}$ bien entrado este en años-. Muchas de las indicaciones atienden a la necesidad de poner de cursiva una expresión o palabra con el objetivo de que el lector entienda que no es la acepción habitual, como se lee en el siguiente pasaje de la Revista de España:

Ha dicho y dicho bien: Fontaine, en efecto, cayó herido de muerte en el momento en que el Duque de Anguien pasó á atacar la batalla, y desde los primeros tiros que en la batalla se cruzaron. Lo único que echo de menos en la frase citada de El Solidario y su tiempo, es que se hubiera debido imprimir la palabra batalla como aquí, en bastardilla, y esto con el fin de no dar lugar á dudas ó torcida interpretación; pues pocos saben, como sabe el Sr. D. Antonio Cánovas del Castillo tan al corriente de todos los tecnicismos militares que batalla, militarmente hablando, significa, todo el centro del orden de batalla, siendo "la vanguardia el primer puesto de la batalla", como la retaguardia y la reserva los últimos (Revista de España, enero de 1884, núm. 96, p. 537).

Y con estos mismos motivos de querer resaltar que la expresión sea entendida de otra manera (por ironía), destacamos el siguiente fragmento:

El párrafo precedente, está reproducido tal y como lo publica el diario progresista, y no hay necesidad por cierto de variar el carácter de letra para que salte á primera vista la intencion con que han podido escribirse las palabras habladores, parlanchines, y frases como la última del párrafo en que se habla de la perfidia, de la intriga y de la fuerza como medios por los que algunos hombres ocuparon ciertos puestos, esto es, los ministerios que hoy quieren para sí los progresistas.

Por si acaso no se veia bien la intencion del articulo de La Iberia, este diario ha tenido la humorada de ponerle un pegote final en letra bastardilla, advirtiendo que el artículo se dirige á La Política, y no al partido unionista, en el que hay hombres leales, etc., etc.

Tiene razon El Imparcial, "hay mar de fondo". La conciliacion está en grave peligro (El Pensamiento Español, 2 de junio de 1869, p. 2). 
Los ejemplos en los que un articulista acude a dignificar el uso de la cursiva como forma de focalizar un término que lingüísticamente no se comprendería con una simple lectura son numerosísimos, pero pongamos como botón de muestra el siguiente pasaje:

¿Qué significa eso de poner en letra bastardilla la palabra perseguidor? ¿Significa que El Diario Español quiere dar á entender que el general Zabala no persiguió de veras al general Prim cuando este se pronunció, siendo aquel ministro de doña Isabel, y $E l$ Diario Español defensor de doña Isabel, como ahora lo es de D. Amadeo? (La Esperanza, 17 de enero de 1871, núm. 8033, p. 2).

Sin embargo, a partir de mediados del siglo xIx, la prensa periódica se debate entre los usos correctos gramaticales y aquellos desviados que, sin tanto rigor purista, deberían considerarse castizos. Las manifestaciones halladas, en donde se comparte la necesidad de aceptación o de rechazo de determinadas palabras con el uso de la cursiva, revelan los vaivenes de opinión puristas y progresistas que se desataron en la segunda mitad de la centuria. Sirva de muestra el siguiente pasaje:

Tocante á la ortografía con que sale á la luz este curioso y desconocido opúsculo, debo decir que me he apartado de la que se emplea en el original, comunmente viciosa, pues creo que á nada conduce conservar estan por es tan, hixo por hijo, Cordoua por Córdoba, vno por uno etc., no tratándose, como no se trata aquí, de ningun monumento artístico-literario cuya naturaleza conviene sea trasladada en cuerpo y alma, ó séase con todos sus pelos y señales, á la posteridad; sin embargo, deseoso de no desfigurar, en lo posible, la fisonomía del original, lo he respetado en aquellos pasajes en que, á mi ver, hay error de concepto, si bien incluyendo dentro de paréntesis en letra cursiva aquello que de seguro falta en el original, tal vez por precipitacion al escribirlo (El Averiguador Universal, 28 de febrero de 1882, núm. 76, p. 56).

Y más claro el reproche de barbarismo: 
El afan de que el gobernador dimita hace olvidar á La Vanguardia hasta el castellano.

Desalojar de cuajo, escríbase ó no esta palabra con bastardilla, es un barbarismo.

Prueba al canto.

"De cuajo. mod. adv. De raíz, sacando enteramente alguna cosa del lugar en que estaba arraigada. Usase comunmente con el verbo arrancar" (Diccionario de la lengua castellana, por la Academia española. Ultima edicion).

"Desalojar. a. Echar de un lugar, hacer por fuerza de armas dejar el alojamiento, casa ó sitio donde está alguno alojado ó fortificado" (Diccionario, etc.).

Probado el barbarismo, continuemos (La Dinastía, 17 de septiembre de 1884, núm. 549, p. 5851).

La tendencia purista reaparece también en el siguiente texto:

Al principio del artículo, el citado redactor dice que tiene verdadera debilidad por Paco Lozano, en cuyo velódromo, según él, ha aprendido á montar la mar de gente.

Pase lo de escribir la mar en letras de molde y sin bastardilla, como un rasgo de buen humor del admirador de Lozano. Pero ¿y lo de no encontrar nada notable en el periódico de un vendedor de bicicletas, después de confesar su debilidad por Paco Lozano, vendedor de bicicletas también? (El Deporte Velocipédico, 6 de marzo de 1895, núm. 2, p. 16).

Interesante también es el siguiente documento, publicado en El Enano, en donde se reconoce el uso de la bastardilla en expresiones dialectales, ajenas a la norma de prestigio castellana:

Contestacion. Uno de nuestros colegas periodísticos, copiando la semblanza del espada Gonzalo Mora, inserta en el número próximo anterior del ENANO, pone en letra bastardilla la frase "Es un muchacho muy compuesto" y la critica suponiendo que en el lenguaje andaluz es una ofensa, especialmente para la gente de rumbo. Podrá ser cierta la acepcion que en determinado estilo 
se quiera dar á la palabra compuesto aplicada á un hombre; pero tambien lo es que escrita, como lo está en la semblanza, en castellano y para españoles en general, muy lejos de llevar envuelta la menor ofensa, sirve únicamente para espresar una idea contraria, á saber: que Gonzalo Mora es pulcro, atildado, apuesto, gentil, bien vestido, de buenas maneras, cuyas calificaciones todos equivalen, segun el Diccionario, ó al menos el uso comun, á la de compuesto, que en la semblanza se usa (El Enano, 17 de febrero de 1887, núm. 312, p. 2).

Y como colofón de manifestaciones sobre el uso de la cursiva para alejar un término de la pureza que se le pide a la lengua castellana, añadimos los dos fragmentos siguientes:

Sábenlo Dios y los que tienen la paciencia de leerme, que pongo particular empeño en todos mis escritos, en huir del vocablo extranjero, y que en algunos me atrevo á censurar la manía que tienen apreciabilísimos y distinguidos compañeros periodistas de abusar con premeditación y alevosía de dos ó tres docenas de palabras francesas, inglesas é italianas, que al pasar por las cajas de la tipografía española se desfiguran por completo, sin que les valga la letra bastardilla, de que han menester para colarse de matute en la frase castellana.

Digo esto, porque á los que nos cuesta tanto trabajar en las cuartillas diarias del idioma patrio, y que además, sea por lo que sea, sabemos un poquito de italiano, de francés ó de inglés, por haberlo hablado y escrito durante veinte años consecutivos en la propio [sic] tierra, se nos ponen los nervios en punta cuando tropezamos con esos artículos bilingües ó trilingües que parecen escritos para escarnio de la rica habla castellana (La Época, 28 de septiembre de 1896, p. 1).

La palabra destroyer — según carta que se nos envía-, que se aplicaba antes á los buques ingleses y se escribía subrayándola para indicar su origen extranjero, se usa ya, no tan sólo sin imprimirla en letra cursiva, sino aplicándola á barcos españoles.

Muchos individuos la pronuncian además afrancesándola y dicen destruaier, con lo que la estropean completamente, come- 
tiendo un verdadero ataque á la lengua española, que cuenta con la palabra destructor, que es la que exactamente corresponde á esta clase de buques (La Época, 20 de mayo de 1896, p. 4).

No se trata aquí de dar a conocer el corpus completo de las manifestaciones que hemos extraído de la prensa española de los siglos XVIII y XIX, sino de incluir un conjunto de muestras que adviertan sobre la conciencia de los hablantes de la época en torno al uso de la cursiva como medio de enfatizar lo que es ajeno a la lengua. Una vez que queda probado el uso de este recurso focalizador, correspondería en futuros trabajos desvelar lo que hay detrás de este tipo de letra en documentos concretos (y distinguiendo por tipo de texto), con objeto de entender no solo los movimientos puristas de la lengua, sino también de rescatar pistas para diferenciar entre el uso oral del momento y el escrito.

\section{Conclusiones}

La ciencia filológica vive de la interpretación de los textos, pero también esta debe entender que su objeto de análisis tiene vida propia. El investigador afronta, por ello, la misión de sacar a la luz cualquier detalle que permita desvelar el intríngulis del mecano lingüístico, y no solo desde el punto de vista sincrónico, sino también en su evolución histórica. En este proceso de búsqueda, es bienvenida la incursión de cualquier variable que haga más fácil la comprensión de determinados fenómenos. Pues bien, con este trabajo, hemos querido contribuir a dar un primer paso en el acercamiento a las creencias y actitudes ante la lengua de determinados hablantes de los siglos XVIII y XIX. Es cierto que la observación de los hechos lingüísticos en sí mismos, con abstracción del yo y el tú de la comunicación, permite aventurar hipótesis sobre el trasiego de formas gramaticales, pero también lo es que la puesta en conexión de esos elementos internos con el entorno sociocultural abunda en el porqué de los cambios. Así, en la difícil tarea de destapar la intervención social en la lengua, hemos querido presentar un primer esbozo para el 
análisis de una nueva variable: la conformación tipográfica del texto y, más concretamente, las razones que motivan el uso de la letra inclinada. Este efecto formal pasó de caracterizar tipos de libros (con un contenido específico) a resaltar elementos que se consideraban como ajenos a una unidad textual. Este proceso alienador atribuible a la cursiva, en donde lo focalizado se distancia de las ideas del escritor-agente, podría destapar la creencia ante la lengua del que escribe y de aquel al que se le atribuye la expresión resaltada. Así, bastaría que un autor pusiera de cursiva una palabra, para que - por una ironía, paradójicamente explicitada - se conociera el universo de creencias en torno a ese elemento puesto en foco (desde concepciones puristas a rechazos por motivos diatópicos, diastráticos o diafásicos). Y con objeto de conseguir un mayor grado de refinamiento en esta búsqueda, hemos querido servirnos del concepto de tradiciones discursivas, pues los textos deben ser examinados según el grado de distanciamiento de la oralidad, según la época en la que se haya escrito, según el género, según el medio de transmisión, y un largo etcétera. En nuestro análisis, centrado en la tradición periodística, se han mostrado pertinentes variables como 'autor material'/'redactor o cajista', 'contenido discursivo' (si político, económico, publicitario, literario...), 'época’ y 'tipo de imprenta'. Bien es cierto, no obstante, la dificultad de diferenciar en el campo de la literatura lingüística entre el concepto de tradiciones discursivas y el de tradición textual. Por ello, habríamos de relegar a este último nuestras tres primeras categorías estudiadas y dejar para el primero las ideas que se esconden en la cuarta, que son las más interesantes para el destapamiento de las actitudes ante la lengua.

De la revisión de más de setenta publicaciones periódicas españolas de los siglos XVIII y XIX, hemos querido extraer, en esta primera fase, las opiniones explícitas más representativas sobre el uso de la cursiva en la prensa, pues así podremos, en un futuro, acercarnos con mayor seguridad metodológica a los resaltes particulares de los textos, que revelarán actitudes implícitas ante la lengua. El proceso de alienación que se asocia con la letra inclinada ha permitido reducir el conjunto de opiniones 
a cuatro grupos, de los cuales, el más importante para estudios posteriores, es aquel que justifica su uso en el desvelamiento de una actitud lingüística. La información recogida permite concluir evoluciones tipográficas del género periodístico (desde un uso para expresar las ideas del otro, en donde el redactor o cajista se convertía en agente principal de aplicación [siglo XVIII], hasta la utilización irónica de la cursiva por parte del articulista, con una menor intervención del redactor [siglo XIX]), así como la focalización de términos ajenos a la lengua (en donde se podrían advertir posturas puristas). Ahora se abre, quizá, un camino para el estudio de las actitudes lingüísticas desde una consideración ortotipográfica, que precisará, además, un contraste con las otras tradiciones periodísticas desarrolladas en América durante el siglo XIX. Ahora solo hemos querido rescatar valoraciones, pero queda un trabajo por delante en la búsqueda de ejemplos concretos en los diferentes tipos de textos.

\section{Bibliografía}

Fuentes primarias

Boletín Histórico (1880-1886), Madrid, Arbau y Compañía, disponible en <http://hemerotecadigital.bne.es/details.vm?q= id:0003693891\&lang=es>

Diario de Madrid (1788-1825), Madrid, disponible en $<$ http://hemerotecadigital.bne.es/details.vm?q=id: 0001510462\&lang=es $>$

El Áncora: diario religioso-social, económico-administrativo, literario, mercantil, de noticias y avisos (1850), Barcelona, Pons y Cia.

El Averiguador (1867), Madrid, Aniceto Hidalgo impresor, disponible en <http://hemerotecadigital.bne.es/details.vm?q= id:0026721516\&lang=es>

El Averiguador Universal: correspondencia entre curiosos, literatos, anticuarios, etc. etc. y revista de toda clase de curiosidades (1879-1882), Madrid, Alejandro Gómez Fuentenebro, 
disponible en <http://hemerotecadigital.bne.es/details. vm?q=id:0026724270\&lang=es $>$

El Bascongado (1813-1814), Bilbao, Oficina de Francisco Cándido Pérez Prieto, disponible en <http://hemerotecadigital. bne.es/details.vm?q=id:0004103509\&lang=es>

El Castellano (1836-1846), Madrid, El Castellano, disponible en <http://hemerotecadigital.bne.es/details.vm?q=id: 0029017865\&lang=es $>$

El Censor General (1812), Sevilla, Imprenta de la Calle Vizcaynos, disponible en <http://hemerotecadigital.bne.es/details.vm?q=id:0004828349\&lang=es>

El Conciso (1810), Cádiz, Imprenta de Quintana, disponible en <http://hemerotecadigital.bne.es/details.vm?q=id: 0004198159\&lang=es $>$

El Deporte Velocipédico (1895), Madrid, Hijos de M. G. Hernández, disponible en <http://hemerotecadigital.bne.es/details. vm?q=id:0004198159\&lang=es $>$

El Enano (1885-1887), Madrid, Imprenta de José de Rojas, disponible en <http://bdh.bne.es/bnesearch/biblioteca/El\%20 Enano\%20de\%20Madrid\%20:/qls/0003737526;jsessionid =CDCEB6803C4DC6B0F42279B783F8BF71>

ElPensamiento español:diario de la mañana (1860-1874), Madrid, El Pensamiento Español, disponible en <http://hemerotecadigital.bne.es/details.vm?lang=es\&q=id:0029673081>

Fr. Gerundio (1806-1866), León, Cándido Paramio y Pascual, disponible en <http://hemerotecadigital.bne.es/details. vm?q=id:0004377775\&lang=es $>$

Gaceta Agrícola del Ministerio de Fomento (1876-1894), Madrid, Imprenta de Manuel G. Hernández, disponible en <http:// hemerotecadigital.bne.es/details.vm?q=id:0026664358 \&lang=es $>$

Gazeta del Gobierno de México (1810-1835). Gaceta del Gobierno Supremo de la Federación Mexicana, México, Imp. de Arizpe, disponible en <http://hemerotecadigital.bne.es/ details.vm?q=id:0004620247\&lang=es $>$

Guía de Sevilla (1865-1896), Sevilla, La Andalucía, disponible 
en <http://hemerotecadigital.bne.es/issue.vm?id=0004486 872 \&search $=$ \&lang=es $>$

Gil Blas. Periódico satírico (1864), Madrid, J. Antonio García, disponible en <http://hemerotecadigital.bne.es/details. vm?lang=es\&q=id:0003828497>

La Ciencia Cristiana (1877), Madrid, La Ciencia Cristiana, disponible en <http://hemerotecadigital.bne.es/details. vm?q=id:0025437966\&lang=es>

La Dinastía (1883-1904), Barcelona, La Dinastía, disponible en <http://hemerotecadigital.bne.es/details.vm?q=id: 0001323470\&lang=es $>$

La Época (1849), Madrid, La Época, disponible en <http:// hemerotecadigital.bne.es/details.vm?lang=es\&q=id: 0000000021>

La Escuela Moderna (1891-1934), Madrid, Gras y Compañía, disponible en <http://hemerotecadigital.bne.es/details.vm? $\mathrm{q}=\mathrm{id}$ :0001252896\&lang=es $>$

La Esperanza (1844-1874), Madrid, La Esperanza, disponible en <http://hemerotecadigital.bne.es/details.vm?lang= es\&q=id:0001801754>

La Monarquía (1887), Madrid, Imprenta del Indicador oficial de los caminos de hierro, disponible en <http://hemerotecadigital.bne.es/details.vm?q=id:0003512260\&lang=es $>$

La Unión (1882), Madrid, Imprenta de D. A. Pérez Dubrull, disponible en <http://hemerotecadigital.bne.es/details.vm? $\mathrm{q}=\mathrm{id}: 0004849379 \&$ lang $=\mathrm{es}>$

Mercurio histórico y político (1738-1783), Madrid, Manuel Fernández, disponible en <http://hemerotecadigital.bne.es/ details.vm $\mathrm{o}=\& \mathrm{w}=2171-1097 \& \mathrm{f}=\mathrm{issn} \& \mathrm{l}=500>$

Minerva o el Revisor General (1805), Madrid, Imprenta de Vega y Compañía, disponible en <http://hemerotecadigital.bne. es/details.vm?lang=es\&q=id:0003716626>

Nuevo Diario de Madrid (1821-1823), Madrid, Imprenta de Espinosa, disponible en $<$ http://hemerotecadigital.bne.es/details.vm?q=id:0003550321\&lang=es>

Revista Contemporánea (1876-1907), Madrid, Revista Contemporánea, disponible en <http://hemerotecadigital.bne.es/ details.vm?q=id:0002283020\&lang=es $>$ 
Revista de España (1868), Madrid, Tipografía de Gregorio Estrada, disponible en <http://hemerotecadigital.bne.es/details.vm?q=id:0002715600\&lang=es $>$

Revista de Geografía Comercial (1885-1896), Madrid, Imprenta de Fontanet, disponible en <http://hemerotecadigital.bne. es/details.vm?lang=es\&q=id:0003303316>

Fuentes secundarias

Agheyisi, Rebecca y Joshua Fishman (1970), "Language attitude studies: A brief survey of methodological approaches", Anthropological Linguistics, 12:5, pp. 137-157.

Badía Margarit, Antonio (1960), "Dos tipos de lengua cara a cara", Homenaje a Dámaso Alonso, I, Madrid, Gredos, pp. 115-139.

Blanco de Margo, Mercedes (1991), "Actitudes hacia la lengua en la Argentina. Visión diacrónica", Revista de Lingüística Teórica y Aplicada, 29, pp. 197-214.

Blas Arroyo, José Luis (1999), "Las actitudes hacia la variación intradialectal en la sociolingüística hispánica”, Estudios Filológicos, 34, pp. 47-72.

Conde Silvestre, Juan Camilo (2007), Sociolingüística histórica, Madrid, Gredos.

Consolo, Cecilia (ed.) (2013), Tipografía en Latinoamérica. Orígenes e identidad, São Pablo, Blücher.

Corbeto, Albert y Marina Garone Gravier (2015), Historia de la tipografía. La evolución de la letra desde Gutenberg hasta las fundiciones digitales, Lleida, Milenio.

Coseriu, Eugenio (1977), El hombre y su lenguaje, Madrid, Gredos.

Dietrich, Wolf (1973), Der periphrastische Verbalaspekt in den romanischen Sprachen. Untersuchungen zum heutigen romanischen Verbalsystem und zum Problem der Herkunft des periphrastischen Verbalaspekts, Tubinga, Niemeyer.

EDWARDS, JoHn (1982), "Language attitudes and their implications among English speakers", Attitudes towards Language Variation, Londres, Edward Arnold, pp. 20-33. 
Garone Gravier, Marina (2012), La tipografía en México. Ensayos históricos (siglos XVI al XIX), México, Universidad Nacional Autónoma de México.

Garone Gravier, Marina (2015), El Arte de ymprenta de don Alejandro Valdés (1819). Estudio y paleografía de un tratado de tipografía inédito, México, Foem.

Giles, Howard y Robert N. St. Clair (eds.) (1979), Language and Social Psychology, Oxford, Blackwell.

KaвATEK, Johannes (2000), "Loral et l'écrit — quelques aspects théoriques d'un 'nouveau' paradigme dans le canon de la linguistique romane", en W. Dahmen (ed.), Kanonbildung in der Romanistik und in den Nachbardisziplinen, Tubinga, Narr, pp. 305-320.

Koch, Peter y Wulf Österreicher (2011), Gesproche Sprache in der Romania. Französisch, Italienisch, Spanisch, Gotinga, De Gruyter.

Labov, William (1972), Language in the Inner City, Filadelfia, Pennsylvania University Press.

López Morales, Humberto (1989), Sociolingüística, Madrid, Gredos.

Milroy, James (2001), "Language ideologies and the consequences of standardization", Journal of Sociolinguistics, 5:4, pp. 530-555.

Mourenza, Carmen (1977), Historia de la imprenta en Asturias, Gijón, Ayalga ediciones.

Rivas Zancarrón, Manuel (2010), "Impacto de las reformas ortográficas en la tradición escrita en los siglos XVIII y XIX", en F. Durán López y V. Gaviño Rodríguez (eds.), Gramática, canon e historia literarias, Madrid, Visor, pp. 327-348.

Rivas Zancarrón, Manuel (2017a), “Actitudes ante la lengua en el pensamiento gramatical del siglo XviII. Algunas consideraciones metodológicas en el acceso al objeto de estudio", Boletín de la Sociedad Española de Historiografía Lingüística, 11, pp. 167-191.

Rivas Zancarrón, Manuel (2017b), “Acercamiento metodológico al estudio de las actitudes lingüísticas ante el sistema gráfico en la prensa española del siglo xviII", en J. M. 
Santos Rovira (ed.), Variación lingüística e identidad en el mundo hispanohablante, Lugo, Axac, pp. 11-29.

Rivas Zancarrón, Manuel (2018a), "La forma de los tipos gráficos como instrumento para la expresión de actitudes lingüísticas en la prensa costarricense del siglo XIX”, Boletín de Filología, 53:1, pp. 237-275.

Rivas ZanCARrón, Manuel (2018b), “Panorama general para el estudio de las actitudes lingüísticas ante la ortografía en los espacios de opinión pública de América y España en los siglos XVIII y XIX", Zeitschrift für romanische Philologie, 134:3, pp. 761-793.

Rojas, Darío y TAnia Avilés (2014), "Ideologías lingüísticas en la fraseología del español de Chile: dos momentos, una misma concepción del lenguaje”, Onomázein, 29, pp. 64-77.

Rona, José Pedro (1974), "La concepción estructural de la sociolingüística” en P. Garvin y Y. Lastra (eds.), Antología de estudios de etnolingüística y sociolingüística, México, Universidad Nacional Autónoma México, pp. 203-216.

Rizzini, CARlos (1968), O jornalismo antes da tipografia, São Paulo, Companhia editora nacional.

SARNOFF, IRVING (1966), "Social attitudes and the resolution of motivational conflict", Attitudes, Harmondsword, Penguin, pp. 279-284.

Schlieben-Lange, Brigitte (1973), Soziolinguistik: Eine Einführung, Stuttgart, Kohlhammer.

Schlieben-Lange, Brigitte (1975), Linguistische Pragmatik, Stuttgart, Kohlhammer.

Schilieben-Lange, Brigitte (1983), Traditionen des Sprechens. Elemente einer pragmatischen Sprachgeschichtsschreibung, Stuttgart, Kohlhammer.

Manuel Rivas Zancarrón. Profesor Titular de Lengua española en la Universidad de Cádiz (España). Ha trabajado problemas lingüísticos de diferentes disciplinas como la fonéti- 
ca (Tendencias fonéticas en el español coloquial, Hildesheim: Georg Olms), morfología (Problemas de morfología española, New York: Peter Lang), gramática histórica (Edición y transcripción del Fuero Juzgo) o sociolingüística histórica ("Panorama general para el estudio de las actitudes lingüísticas ante la ortografía en los espacios de opinión pública de América y España", en Zeitschrift für romanische Philologie, 2018, 134-3). Asimismo, ha realizado múltiples estancias de investigación en universidades españolas y extranjeras (Freie Universität Berlin, University of Washington, University of Princeton, Universidad Estatal Lingüística de Moscú, Universidad de Helsinki (Helinsigin Yliopisto), Universidad de París VIII, Universidad de Costa Rica, Universidad de Chile). 